\title{
Implicit motives, explicit traits, and task and contextual performance at work
}

Citation for published version (APA):

Lang, J. W. B., Zettler, I., Ewen, C., \& Hülsheger, U. R. (2012). Implicit motives, explicit traits, and task and contextual performance at work. Journal of Applied Psychology, 97(6), 1201-1217.

https://doi.org/10.1037/a0029556

Document status and date:

Published: 01/11/2012

DOI:

10.1037/a0029556

Document Version:

Publisher's PDF, also known as Version of record

Document license:

Taverne

Please check the document version of this publication:

- A submitted manuscript is the version of the article upon submission and before peer-review. There can be important differences between the submitted version and the official published version of record.

People interested in the research are advised to contact the author for the final version of the publication, or visit the DOI to the publisher's website.

- The final author version and the galley proof are versions of the publication after peer review.

- The final published version features the final layout of the paper including the volume, issue and page numbers.

Link to publication

\footnotetext{
General rights rights.

- You may freely distribute the URL identifying the publication in the public portal. please follow below link for the End User Agreement:

www.umlib.nl/taverne-license

Take down policy

If you believe that this document breaches copyright please contact us at:

repository@maastrichtuniversity.nl

providing details and we will investigate your claim.
}

Copyright and moral rights for the publications made accessible in the public portal are retained by the authors and/or other copyright owners and it is a condition of accessing publications that users recognise and abide by the legal requirements associated with these

- Users may download and print one copy of any publication from the public portal for the purpose of private study or research.

- You may not further distribute the material or use it for any profit-making activity or commercial gain

If the publication is distributed under the terms of Article $25 \mathrm{fa}$ of the Dutch Copyright Act, indicated by the "Taverne" license above, 


\title{
Implicit Motives, Explicit Traits, and Task and Contextual Performance at Work
}

\author{
Jonas W. B. Lang \\ Maastricht University \\ Christian Ewen \\ University of Bonn
}

\author{
Ingo Zettler \\ University of Tübingen \\ Ute R. Hülsheger \\ Maastricht University
}

\begin{abstract}
Personality psychologists have long argued that explicit traits (as measured by questionnaires) channel the expression of implicit motives (as measured by coding imaginative verbal behavior) such that both interact in the prediction of relevant life outcome variables. In the present research, we apply these ideas in the context of industrial and organizational psychology and propose that 2 explicit traits work as channels for the expression of 3 core implicit motives in task and contextual job performance (extraversion for implicit affiliation and implicit power; explicit achievement for implicit achievement). As a test of these theoretical ideas, we report a study in which employees $(N=241)$ filled out a questionnaire booklet and worked on an improved modern implicit motive measure, the operant motive test. Their supervisors rated their task and contextual performance. Results support 4 of the 6 theoretical predictions and show that interactions between implicit motives and explicit traits increase the explained criterion variance in both task and contextual performance.
\end{abstract}

Keywords: power, affiliation, achievement, imaginative verbal behavior, job performance

Industrial and organizational (IO) psychologists have long and repeatedly debated the degree to which personality characteristics predict success at work (e.g., Barrick, Mount, \& Judge, 2001; Guion \& Gottier, 1965; Morgeson et al., 2007; Ones, Dilchert, Viswesvaran, \& Judge, 2007; Tett \& Christiansen, 2007). The empirical basis for these debates has primarily been research that has investigated relationships between explicit personality measures and job performance criteria. Explicit personality constructs are typically assessed with self- or peer-report questionnaires of personality-describing words or statements, and most explicit personality constructs are closely related to the trait concept (Allport, 1937; Pervin, 1994a, 1994b; Winter, John, Stewart, Klohnen, \& Duncan, 1998). Although there is no universally accepted defini-

This article was published Online First August 6, 2012.

Jonas W. B. Lang, Department of Work and Social Psychology, Faculty of Psychology and Neuroscience, Maastricht University, Maastricht, The Netherlands; Ingo Zettler, Center for Educational Science and Psychology, University of Tübingen, Tübingen, Germany; Christian Ewen, Department of Industrial, Organizational and Economic Psychology, Institute of Psychology, University of Bonn, Bonn, Germany; Ute R. Hülsheger, Department of Work and Social Psychology, Faculty of Psychology and Neuroscience, Maastricht University.

We thank Christian Helm and Johannes Kleikamp for their help in collecting and entering data and Nicola Baumann, Anasthasios Chasiotis, and Jan Hofer for advice and training regarding the scoring of the operant motive test.

Correspondence concerning this article should be addressed to Jonas W. B. Lang, Department of Work and Social Psychology, Faculty of Psychology and Neuroscience, Maastricht University, P.O. Box 616, 6200 MD Maastricht, The Netherlands. E-mail: Jonas.Lang@maastrichtuniversity.nl tion of the trait concept, most authors have emphasized that explicit traits capture typical and situational-consistent individual differences in behavior (Pervin, 1994a, 1994b; Winter et al., 1998).

A limitation of focusing on explicit personality dispositions such as explicit traits is that considerable evidence exists supporting the idea that the human personality includes not only explicit personality dispositions but also a set of implicit personality dispositions (e.g., Brunstein \& Maier, 2005; Kehr, 2004; Winter et al., 1998). Research on implicit personality characteristics has investigated a variety of implicit personality constructs. A large proportion of the research in this area, however, has focused on three constructs, also known as the implicit Big 3 motives (Kehr, 2004), that include the power motive, the affiliation motive, and the achievement motive. Implicit motives are typically described as "wishes and desires" (Winter et al., 1998, p. 231) that are not directly accessible to awareness (McClelland, Koestner, \& Weinberger, 1989; Winter et al., 1998).

Although earlier personality research typically focused on studying either implicit or explicit personality characteristics, recent personality research suggests that an integrative perspective that combines implicit and explicit characteristics is most fruitful for understanding behavior. The core principle that underlies this idea is the channeling hypothesis (Bing, LeBreton, Davison, Migetz, \& James, 2007; Brunstein \& Maier, 2005; Winter et al., 1998). This hypothesis suggests that implicit dispositions can be expressed in multiple ways and that explicit dispositions shape (or channel) the way implicit dispositions are expressed in behavior. A high implicit motive disposition is consequently most strongly expressed in behavior when the person also has a comparatively high level of a functionally related explicit disposition. 
The notion of channeling suggests that the most complete picture of personality emerges when one systematically links and jointly studies explicit and implicit dispositions in the prediction of behavior. Adopting this idea, several IO researchers have suggested that assessing implicit personality characteristics and studying channeling effects may be a promising approach to move beyond the frequently modest relationships between explicit personality characteristics and job performance, and they have called for empirical research that examines these theoretical ideas (Bing, LeBreton, et al., 2007; Johnson \& Tan, 2009; Kanfer, 2009; Kehr, 2004; McClelland, 1993). Following this call, some IO psychologists have recently started to include implicit personality measures tapping implicit aggression in applied research to investigate interactions between implicit and explicit aggression measures in the prediction of job performance criteria (Bing, Stewart, et al., 2007; Frost, Ko, \& James, 2007).

In this article, we build on this previous work on channeling effects in the context of IO psychology and investigate the joint role of the implicit Big 3 motives and explicit personality characteristics in the prediction of two core job performance criteria. Task performance captures core required job activities, and contextual performance includes job-related behaviors that contribute to the organization's social and psychological climate (Borman \& Motowidlo, 1997; Sackett \& Lievens, 2008). Our theoretical contribution is the development of specific hypotheses regarding channeling effects between Big 3 motive dimensions and explicit personality characteristics in the prediction of task and contextual job performance. In developing hypotheses, we build on previous theoretical work and research conducted in other settings (e.g., Bing, LeBreton, et al., 2007; Brunstein \& Maier, 2005; Winter et al., 1998). We propose in particular that extraversion channels the expression of the implicit affiliation motive and the implicit power motive in task and contextual performance and that explicit (or self-attributed) achievement works as a channel for the implicit achievement motive's effect on these job performance criteria.

The empirical contribution of this paper is a study testing these theoretical ideas by linking employees' self-reports of their explicit personality characteristics and employees' implicit Big 3 motives with evaluations of their task and contextual performance by their supervisors. This study is the first of which we are aware that investigates interactive relationships between the Big 3-as core implicit personality dimensions - and explicit personality dimensions in the prediction of task and contextual job performance. Our study addresses the complexities in measuring the implicit Big 3 motives by using Kuhl and Scheffer's (2002) operant motive test, an improved modern measure of the Big 3 motives, and by modeling the psychometric response process in this measure with a Thurstonian item-response theory model that builds on recent advancements in the modeling and scoring of complex response patterns (Brown \& Maydeu-Olivares, 2011; Böckenholt, 2001).

\section{Implicit Motives and Explicit Traits}

Theories on the interplay between implicit and explicit personality characteristics can best be understood on the basis of the theoretical distinction between implicit motives and explicit traits. Personality psychologists have long argued that it is useful to differentiate between motives and traits (McClelland, 1951; Pervin, 1994a, 1994b; Winter et al., 1998). Some authors have sug- gested linking motives to implicit personality measures and linking traits to explicit questionnaire measures of personality (McClelland, 1951; Winter et al., 1998). This classification corresponds to the initially preferred measurement approaches in the respective research tradition in personality psychology - questionnaires in the trait research tradition founded by Gordon Allport (1937) and implicit measures in the motive research tradition established by Henry Murray (Murray, 1938; also see McClelland, Atkinson, Clark, \& Lowell, 1953). Throughout this paper, we refer to motives measured by implicit measures as implicit motives and to traits measured with questionnaires as explicit traits. This approach ensures conceptual clarity, as the terms trait and motive have frequently been used in different contexts and meanings.

\section{Explicit Traits}

Most authors emphasize that traits capture typical and consistent individual differences in behavior (Pervin, 1994a, 1994b; Winter et al., 1998). These descriptive elements correspond to Emmons' (1989) definition of traits as "stylistic and habitual patterns of cognition, affect, and behavior" (p. 32). Explicit traits that are measured with self- or peer-report questionnaires are explicit in the sense that people are aware of their explicit traits and that accounts they provide about their explicit traits are typically valid (McClelland, 1951; Winter et al., 1998).

Core elements of the trait definition, the situational consistency and stability of traits, have been debated in the 1970s (Donnellan, Lucas, \& Fleeson, 2009). However, there is now an extensive empirical literature suggesting that traits show notable degrees of consistency over time (e.g., Roberts \& DelVecchio, 2000) and across situations (Donnellan et al., 2009).

\section{Implicit Motives}

In contrast to traits that capture typical and consistent patterns, implicit motives are typically described as "wishes and desires" (Winter et al., 1998, p. 231). These ideas are also captured in Emmons' definition of motives as "the disposition to be concerned with and to strive for a certain class of incentives or goals" (Emmons, 1989, p. 32, also see Winter et al., 1998). Implicit motives have traditionally been assessed by asking respondents to spontaneously generate fantasy stories in response to ambiguous pictures. This imaginative verbal behavior is subsequently scored for motivational content by trained experts. An early measure of imaginative verbal behavior and the conceptual basis for many later measurement approaches is Murray's Thematic Apperception Test (TAT; Murray, 1938).

Implicit motives are implicit in the sense that responses are frequently not directly accessible to awareness, either because their content is entailed in idealized self-conceptions or because people defend against knowledge of their implicit motives (McClelland et al., 1989; Winter et al., 1998). It is important to distinguish between implicit motives and motives that are experienced as conscious intentions or strivings (Austin \& Vancouver, 1996; Sheldon, Ryan, Deci, \& Kasser, 2004). This distinction is relevant because explicit representations of motives in questionnaires are typically related to explicit trait questionnaires (Engeser \& Langens, 2010; Winter et al., 1998). In contrast, research suggests that implicit motives and explicit traits are commonly not correlated 
even when they tap the same class of behavior (Brunstein \& Maier, 2005; McClelland et al., 1989; Spangler, 1992; Winter et al., 1998). Several authors have argued that missing correlations between explicit traits and implicit motives are not surprising from a theoretical perspective because similar trait-defining behavior may be motivated by different or even opposing implicit motivational tendencies (e.g., McClelland et al., 1989; Winter et al., 1998). To illustrate this idea, Winter et al. (1998) described the example of the two extraversion items "I like large noisy parties" and "I truly enjoy myself at social functions." People with a high affiliation motive may like to go to parties and social functions because parties and social functions present an opportunity to establish and enjoy relationships with others. Conversely, people with a low affiliation motive might also endorse the items because parties and social functions are essentially impersonal events where one can easily avoid deeper and closer conversations by walking away, getting a drink, and so forth.

Just as the stability and consistency of explicit traits were questioned during the 1970s, a debate on the consistency and stability of measures of implicit motives emerged during this decade (Entwisle, 1972; Schultheiss \& Brunstein, 2010). This debate was fueled by a paper reporting low levels of reliability for implicit measures based on coding imaginative verbal behavior like classic versions of the TAT (Entwisle, 1972). Motivational researchers have addressed the theoretical critique by suggesting that implicit motives are dynamic in the sense that they are aroused by situational cues. The activation of a particular implicit motive by a particular type of situational cue, however, is actually relatively stable within similar types of situations for each person, such that persons respond to similar pictorial cues in similar ways (Atkinson, 1982; Schultheiss, Liening, \& Schad, 2008; Winter et al., 1998).

In addition, personality researchers have advanced the measurement of implicit motives by developing a second generation of measures for assessing implicit motives through coding imaginative verbal behavior. The emergence of second-generation measures has led to a resurrection of personality research on implicit motives (e.g., Baumann, Kaschel, \& Kuhl, 2005; Hagemeyer \& Neyer, 2012; Hofer et al., 2010; Schultheiss et al., 2005). Prominent examples for second-generation measures are contemporary versions of McClelland's Picture-Story Exercise (Pang, 2006; Schultheiss \& Pang, 2007; Winter, 1994), which rely on new scoring manuals by Winter (1994) or Pang (2006), and Kuhl and Scheffer's (2002) operant motive test (OMT). Like earlier methods for assessing implicit motives (e.g., Heckhausen, 1963; McClelland et al., 1953), second-generation measures ask respondents to spontaneously generate stories in response to ambiguous pictures and largely focus on assessing the Big 3 motives (power, affiliation, and achievement). Unlike earlier measures, however, secondgeneration measures overcome some earlier problems with scoring the content of fantasy stories (Baumann et al., 2005; Schultheiss \& Pang, 2007) by (a) using improved, simplified, and integrated scoring manuals that provide guidance on distinguishing between the three major implicit motives (affiliation, achievement, and power); (b) building on a more refined theoretical understanding of picture content in selecting pictures; and (c) using the time that is available until people start to focus away from motive-relevant content more effectively by asking people to write only a short description rather than a full story for a larger number of pictures (Scheffer, Kuhl, \& Eichstaedt, 2003; Schultheiss \& Pang, 2007).
There is now evidence that second-generation measures of implicit motives such as modern versions of the Picture-Story Exercise and the OMT have higher reliability than the values observed by Entwisle (1972). A meta-analysis on the test-retest reliability of the Picture-Story Exercise (Schultheiss \& Pang, 2007) and studies on the OMT (Scheffer et al., 2003) have found that these measures typically show test-retest reliabilities that are in the range of test-retest reliabilities for explicit trait measures (Roberts \& DelVecchio, 2000). Findings on the internal consistency of implicit measures based on coding imaginative verbal behavior have typically been less favorable and have typically shown Cronbach's $\alpha$ values below .40 for early measures (Entwisle, 1972; Tuerlinckx, De Boeck, \& Lens, 2002) but also for more recent versions of the Picture-Story Exercise (Schultheiss et al., 2008). However, Scheffer et al. (2003) and an anonymous reviewer of this paper have pointed to the fact that the response process in measures that rely on coding imaginative verbal behavior resembles a forcedchoice process and that Cronbach's $\alpha$ is not a measure of internal consistency that adequately reflects forced-choice response processes (Brown \& Maydeu-Olivares, 2011). A picture may activate different motives, but only the strongest of these motives ultimately shapes the content of the verbal account. In line with this idea, Scheffer et al. found that OMT scores have notable levels of Cronbach's $\alpha$ when analyses are restricted to people with high or low scores for each motive. However, this approach is not optimal because not all data are considered. We have therefore applied a recently developed methodology for modeling forced-choice processes that builds on Thurstonian item-response models for paired comparisons (Böckenholt, 2001; Brown \& Maydeau-Olivares, 2011) to the data of the present study to adequately model the underlying response processes. Using this methodology, empirical item-response theory estimates of internal consistency reliability were considerably higher (above .60) for all three latent motives measured with the operant motive test in the present study. We provide details on these analyses in the Method section of this paper.

\section{Channeling Effects}

In the preceding section, we mentioned research suggesting that explicit trait and implicit motives are frequently not associated even when they concern the same behavioral domain. The channeling hypothesis suggests that implicit motives and explicit traits nevertheless work together in influencing behavior. That is, the typical behavioral patterns captured in explicit traits may allow people to act out and pursue the desires and wishes implicit motives entail. Explicit traits consequently function as behavioral channels through which implicit motives can be expressed (Bing, LeBreton, et al., 2007; Bing, Stewart, et al., 2007; Winter et al., 1998).

The channeling hypothesis suggests that considering implicit motives and explicit traits jointly provides a more complete picture of people's personality and is frequently important for understanding behavior. In the following sections, we therefore present specific hypotheses on how explicit personality characteristics channel effects of the Big 3 motives (power, affiliation, and achievement) on performance at work. The majority of our theoretical arguments apply to both core job performance criteriatask and contextual performance-and the nature of the predictions is similar for the two criteria. Table 1 provides an overview of the core theoretical ideas. In understanding and illustrating 
Table 1

Overview of Prototypical Combinations of Implicit Motives and Explicit Traits and Their Hypothesized Consequences at Work

\begin{tabular}{|c|c|c|}
\hline Implicit motive & High & Low \\
\hline & \multicolumn{2}{|c|}{ Extraversion } \\
\hline \multicolumn{3}{|l|}{ Affiliation } \\
\hline High & Happy socially related work & Lonely work \\
\hline Low & Socially distracted work & Happy independent work \\
\hline \multicolumn{3}{|l|}{ Power } \\
\hline High & Directed social involvement & Undirected social involvement \\
\hline Low & Desire for influence; cynical frustration & Socially uninvolved independent work \\
\hline & \multicolumn{2}{|c|}{ Explicit achievement } \\
\hline \multicolumn{3}{|l|}{ Achievement } \\
\hline High & $\begin{array}{l}\text { Takes on challenging work tasks and goals and has } \\
\text { the motivational energy to strive for them }\end{array}$ & $\begin{array}{l}\text { Does not take on challenging tasks at work; } \\
\text { does not derive satisfaction of implicit } \\
\text { need for achievement }\end{array}$ \\
\hline Low & $\begin{array}{l}\text { Takes on challenging work tasks and goals but lacks } \\
\text { the motivational energy to strive for them over } \\
\text { extended periods of time }\end{array}$ & $\begin{array}{l}\text { No work achievement values and no energy } \\
\text { for them; (individual) profit/utility- } \\
\text { oriented work; motivation from external } \\
\text { rewards }\end{array}$ \\
\hline
\end{tabular}

channeling effects, it is frequently helpful to develop and illustrate theory in terms of prototypical trait-motive combinations (Bing, LeBreton, et al., 2007; Bing, Stewart, et al., 2007; Winter et al., 1998). In truth, a continuum exists for implicit motives and for explicit traits such that many intermediate types exist, and it is therefore important to perform statistical analyses using the full continua. However, for developing theory, it is frequently sufficient to focus on the four different combinations of high and low implicit motive and high and low explicit trait.

\section{Implicit Affiliation Motive $\times$ Extraversion}

The affiliation motive is a social motive and captures a deep and implicit desire for acceptance and love by others (Langner \& Winter, 2001; Schultheiss, 2008; Winter et al., 1998). People with high affiliation scores typically show more positive interpersonal behavior toward people they like (Schultheiss, 2008). The reason is that high-affiliation-motive individuals derive more satisfaction from their social relationships and consequently do more to establish, maintain, and nurture these relationships. For instance, research has shown that people with high affiliation motive scores typically make more eye contact with others in noncompetitive social situations (Exline, 1963), are more willing to make concessions toward important others (Hardy, 1957; Langner \& Winter, 2001), and have more positive feelings toward people with opinions similar to their own (Byrne, 1962). In contrast, high-affiliation individuals typically show stronger avoidance behavior toward people they do not like or perceive as rejecting, such as limiting eye contact with them, avoiding their company, or reducing similarities in opinion with them (Byrne, 1961; Burdick \& Burnes, 1958; Exline, 1963).

A prominent idea in the literature is that extraversion typically channels the expression of the affiliation motive in behavior (Winter et al., 1998). Extraversion is a broad explicit personality trait included in most personality taxonomies. People high in extraversion are dominant, like to engage in social activity, are sociable and high in positive emotionality, show high activity, and are focused on their external surrounding (e.g., John, Naumann, \& Soto, 2008). Winter et al. (1998) have argued that these characteristics help people with a high affiliation motive to initiate the social activities and interactions they need to build the deep relationships with others they desire.

We suggest that this general mechanism also influences performance at work, because the vast majority of jobs include interactions with coworkers and supervisors and because research suggests that work is a source of important social relationships for most people (Morgeson \& Humphrey, 2006; Wrzesniewski, Dutton, \& Debebe, 2003). It is likely that people with a high implicit affiliation motive and high extraversion use the social opportunities in their work environment and develop intense and wellfunctioning social relationships with their close colleagues and supervisors. Their affiliation motive could motivate them to maintain and nurture these relationships by fulfilling expectations of their close supervisors and colleagues, such that persons with high affiliation and extraversion will display increased task and contextual performance at work. In addition, the social relationships with colleagues and supervisors likely lead to a higher degree of interconnectedness between work and personal life that could help extraverted persons with high implicit affiliation to gather jobrelated information from coworkers, friends, and supervisors in their leisure time.

In contrast to extraverts with a high affiliation motive, extraverts with a low affiliation motive likely have reduced job performance. These people combine an extraverted tendency to initiate social contact and social interactions with a limited interest in building deep and lasting relationships with others. This combination is likely problematic for task and contextual performance because extraverted behavior likely consumes time. However, extraverts with low implicit affiliation are unlikely to feel deep social connectedness and a resulting desire to meet expectations from relationship partners that would compensate for the reduced on-task time at work. Furthermore, their behavior may alienate others who misinterpret their extraverted behavior as a desire to build a relationship or friendship with 
them in the beginning and are later disappointed by their missing interest in nurturing this relationship.

Although the affiliation motive likely has a positive effect on performance when extraversion is high, it is likely that this relationship reverts when extraversion is low. People with high affiliation and low extraversion desire and fantasize about wellfunctioning social relationships to others. However, because of their lack of extraverted behavior their motivational need largely remains unfulfilled and they are likely to feel lonely and rejected. This situation likely has adverse consequences for both task and contextual performance, because feeling frustrated, not appreciated, and not liked by others in their organization will likely diminish the effort they spend at work. In addition, high-affiliation individuals' tendency to engage in avoidance behaviors such as limiting eye contact and taking opposing opinions when they feel rejected may constitute an additional mechanism that limits performance for people with high affiliation and low extraversion. Research suggests that coworkers and supervisors tend to react negatively to persons who feel depressed and frustrated (e.g., Lang, Bliese, Lang, \& Adler, 2011).

In contrast to introverts with a high implicit affiliation motive, introverts with low implicit affiliation pair a limited desire to develop relationships to others with a corresponding limited amount of actions directed toward initiating social contact and social interactions; in other words, their introverted behavior channels the expression of their limited desire for affiliation. At the workplace, people with this combination likely prefer to work largely on their own and commonly initiate social interactions only when these are needed to exchange relevant work-task-related information. It is consequently likely that these individuals have a limited amount of close interpersonal relationships with coworkers and supervisors but are comfortable with this status. This situation will likely be beneficial for task performance in most jobs, because it enables introverts with low implicit affiliation to spend more time on the core work tasks assigned to them. This mechanism could, in principle, extend to contextual performance when introverts with low implicit affiliation perceive contextual behaviors such as helping others to be a part of their job responsibilities and use their increased available time not only for core job tasks.

Hypothesis 1: The affiliation motive is more positively related to (a) task performance and (b) contextual performance when extraversion is high than when extraversion is low.

\section{Implicit Power Motive $\times$ Extraversion}

Persons with a high power motive derive pleasure from having impact on other persons or groups and seek to limit others' impact on themselves (Schultheiss, 2008). High-power individuals typically have a stronger tendency to repeat behaviors that helped them to dominate others and strive to avoid behavior that led to past defeats to a stronger degree. In contrast to laypersons' conceptions of people seeking power, high-power-motive persons are not generally dominant and aggressive (Schultheiss \& Brunstein, 2002; Schultheiss et al., 2005). Rather, high-power individuals typically acquire behaviors that are effective in persuading and influencing others and apply these behaviors according to the situational needs. For instance, in a study in which high- and low-power individuals gave a short speech while being videotaped and rated by judges, Schultheiss and Brunstein (2002) found that high-power individuals tended to use more effective gesturing and thereby had a more lasting impact on others. Highpower individuals are not necessarily interested only in maximizing their own benefit when they seek to influence others. Instead, their desire is also frequently directed toward having a positive impact for others, their organizations, or their nations. Research on the powermotive dispositions of U.S. presidents generally suggests that presidents with higher power-motive scores show higher presidential performance on measures such as ratings of encyclopedia entries (House, Spangler, \& Woycke, 1991) and direct ratings of success by historians (House et al., 1991; Winter, 1987).

Researchers have argued that extraversion channels the power motive's relationship with behavior (Winter et al., 1998). We suggest that this notion can be extended to the prediction of task and contextual performance at work. In so doing, we build on research on influence tactics at work suggesting that influencing others is an important behavior requirement in most work environments (e.g., Yukl \& Falbe, 1990).

We suggest in particular that the relationship between the power motive and task and contextual performance at work is high when extraversion is also high. It is likely that people with high implicit power motivation and high extraversion use the time they spend in social interactions to make more organized and goal-focused attempts to influence others in social interactions at work in order to increase their benefit, achieve their career goals, and achieve important outcomes for their organization. Extraverts with a low implicit power motive, in contrast, engage in time-consuming extraverted behavior at work but are unlikely to gain benefit for themselves, their organizations, and their coworkers from these social interactions because their extraverted behavior is not goaldirected. When extraversion is high, high power motivation should consequently lead to increased task and contextual performance through extraverted behavior as a channel for the expression of the implicit power motive.

This relationship likely changes when extraversion is low, such that channeling effects of extraverted behavior are absent. People with high power motivation but low extraversion are unlikely to have the impact on important decisions in organizations that they seek because they do not spend enough time in social interactions in which they have the chance to actually influence others. Because research suggests that people with high power motivation tend to feel frustrated when they do not have the amount of influence they seek (Schultheiss et al., 2005), introverts with high power motivation are more likely to become frustrated with their coworkers and supervisors. This may lead to deteriorated task and contextual performance, and these individuals may engage in desperate and or cynical attempts to change organizational decisions. In contrast, introverts with low power motivation are likely comfortable with the fact that they have limited influence on important organizational decisions and will more readily follow orders from supervisors and requests from coworkers.

Hypothesis 2: The power motive is more positively related to (a) task performance and (b) contextual performance when extraversion is high than when extraversion is low. 


\section{Implicit Achievement Motive $\times$ Explicit Achievement}

In contrast to the affiliation and power motives, the achievement motive does not require the presence of others. It is important to differentiate between laypersons' conceptions of achievement motivation and the psychological achievement motivation concept. The psychological construct captures behavior that is executed because a person is concerned with meeting a standard of excellence (McClelland et al., 1953). Behavior that is directed only toward gaining external rewards (e.g., money) is not achievement motivated in the psychological sense.

Persons with a high implicit achievement motive derive satisfaction from mastering tasks independently in achievement-related situations (i.e., situations in which people are concerned with a standard of excellence; Brunstein \& Maier, 2005; Schultheiss, 2008). The implicit motive energizes spontaneous impulses to act in such situations and is activated by incentives related to performing the task itself (McClelland et al., 1989; Spangler, 1992). People with a high implicit need to achieve typically use self-set internal standards to evaluate their task performance (e.g., Brunstein \& Maier, 2005).

Laboratory research suggests that persons' explicit evaluations of their own achievement motivation can have a channeling effect on the relationship between the implicit achievement motive and performance (Bing, LeBreton et al., 2007; Brunstein \& Maier, 2005). Like other implicit motives and explicit traits covering the same domain, the implicit achievement motive and explicit achievement are two constructs that are typically not correlated and that function in fundamentally different ways (Bing, LeBreton, et al., 2007; Brunstein \& Maier, 2005; Spangler, 1992). Persons with high explicit achievement typically believe that achievement situations provide them with positive affective experiences. Researchers have suggested that they do so because they believe that they have high abilities (Brunstein \& Maier, 2005; Kukla, 1978; Trope, 1986). In contrast to the implicit achievement motive, explicit achievement is activated by social-extrinsic prompts and incentives (e.g., persons that stress the importance to show high achievement) bringing achievement values to cognitive attention (McClelland et al., 1989). Explicit achievement therefore predicts achievement-related task choices, decisions to continue working on achievement-related tasks, and increased effort for short periods of time in situations with social-extrinsic pressures (Brunstein \& Maier, 2005; Schultheiss, 2008).

Brunstein and Maier (2005) have developed a theoretical framework for predicting how and under which circumstances explicit achievement motivation channels effects of implicit achievement motivation on performance. This framework builds on Nicholls' (1984) theoretical distinction between task- and ego-focused situations. In task-focused settings (i.e., tasks without social-extrinsic pressures), the implicit motive and explicit achievement act independently, such that people with explicit achievement seek to assess their abilities relative to others (Trope, 1986) and people with implicit achievement motivation seek to improve their abilities. In contrast, in settings with ego-relevant incentives (i.e., tasks with social-extrinsic pressures), explicit achievement channels the effect of the implicit achievement motive on performance. Ego-relevant incentives are socially desirable outcomes-such as having high intelligence, having success at school, and achieving success in life-and are related to social comparison. In ego-focused settings, people with high explicit achievement wish to appear to have as much ability as possible (Kukla, 1978), and this explicit desire channels the energy of the implicit achievement motive toward the goal of pursuing the relevant outcome.

Because job performance and occupational success are egorelated life outcomes (Brunstein \& Maier, 2005), it is likely that job settings in general activate explicit achievement such that it channels the effect of the implicit achievement motive on performance. People who possess high implicit and high explicit achievement are likely to take on achievement-related and challenging work tasks and duties in order to demonstrate their abilities and should then be able to succeed on these tasks by using their implicit achievement motive to energize their behavior. They should consequently show high task performance and are also likely to feel more capable in helping and supporting others in fulfilling their work tasks. In contrast, people with high explicit achievement but a low implicit achievement motive will not have the motivational energy to maintain high effort over extended periods of time on the achievement-relevant type of tasks they choose (McClelland et al., 1989; Spangler, 1992).

A different pattern of predictions emerges when explicit achievement is low. In this situation, one could predict either a missing relationship between the implicit achievement motive and task and contextual performance or a negative relationship. A negative relationship could emerge because people with a high implicit achievement motive have a desire to satisfy their implicit need for achievement. However, achievement-related task choices are predicted only by explicit achievement and not by the implicit achievement motive (Brunstein \& Maier, 2005). Consequently, people low in explicit achievement motivation but high in implicit achievement motivation do not actively take on challenging tasks that allow them to fulfill their implicit motivational need at work and as a result may feel frustrated and have reduced levels of positive affect and performance (Baumann et al., 2005; Kehr, 2004; McClelland et al., 1989). This idea is in line with laboratory research suggesting that persons low in explicit achievement but high in the implicit achievement motive cannot derive satisfaction from their successes in settings with social-extrinsic pressures like work settings (Brunstein \& Maier, 2005; Experiment 3) and with a meta-analysis suggesting that the implicit achievement motive frequently has a negative effect on performance in settings with social-extrinsic pressure (Spangler, 1992).

Hypothesis 3: The implicit achievement motive is more positively related to (a) task performance and (b) contextual performance when explicit achievement is high than when explicit achievement is low.

\section{Method}

\section{Participants and Procedure}

The participants were a diverse sample of German employees from various organizations and occupational backgrounds. Two research assistants and the third author asked people they knew either personally or through social networking sites to participate in the study. In addition, they went to shops and public offices in the city center of larger cities in the west of Germany (typically in 
the morning of working days because employees and supervisors were least busy then). In the first step of the recruiting process, employees were asked to participate in a scientific study on work motivation and performance. When this was possible, the supervisors were also directly approached and asked to participate. A total of 520 employees agreed and were given (either directly or via postal mail when they were contacted via social networking sites) an envelope containing a larger and a smaller questionnaire booklet, two stamped return envelopes, and candy (participants received no monetary reward). The instruction asked them to hand the smaller booklet and one return envelope to their immediate supervisor. In addition, the instruction asked the employees to fill out the other booklet and return it using the other return envelope. Participants could provide their e-mail addresses in order to receive a summary of the findings of the study via e-mail.

Envelopes were returned by 272 employee and 248 supervisors. A total of 241 complete dyads with both an employee and a supervisor envelope were available for analysis. The employees (147 female, 94 male) in these dyads were between 18 and 69 years of age $(M=35.46, S D=10.91)$, worked $M=36.23 \mathrm{hr}$ per week on average $(S D=11.86 \mathrm{hr})$, and had been in their organizations for an average of $M=7.94$ years $(S D=9.55$ years). We asked employees to indicate their job using an open question. Seventeen worked in sales, 39 were clerks, 13 worked in public administration, six worked in personnel training, six were business consultants, 19 were engineers or technicians, seven were managers, two were lawyers, four were tax accountants, seven were banking and financial employees, 24 were physicians and nurses, three were dentists or dentist support personnel, five were pharmacists, 21 were opticians, 34 were school or kindergarten teachers, nine were college teachers or instructors, and five were social workers. Eleven persons provided a job description that combined jobs or a job description indicating their level in the organizational hierarchy but not the nature of their jobs.

On average, supervisors indicated that they had been working with their employees for $M=4.64$ years ( $S D=6.27$ years). The majority of the supervisors reported that they frequently interacted with their employees ( $n=163$ at least once a day; $n=46$ at least once a week).

\section{Implicit Motive Measurement and Coding}

The affiliation motive, the power motive, and the achievement motive were measured with the operant motive test (OMT; Kuhl \& Scheffer, 2002; Scheffer et al., 2003). The OMT asks respondents to look at a total of 15 ambiguous pictures (see Kuhl \& Kazén, 2008, for examples) showing one or more persons, mark one of the persons shown, and answer the two questions "What is important for the person in this situation and what is the person doing?" and "How does the person feel and why does the person feel this way?" OMT responses are coded by assigning them to one of 15 motive categories based on the criteria specified in the coding manual. The 15 motive categories include three approach components, one in-between category, and one avoidance category for each motive. For the present research, we solely focused on the approach dimensions of each motive and consequently aggregated the approach responses for each of the three motives (encounter, sociability, and networking for affiliation; leadership, recognition, and self-assertion for power; flow, standard of excellence, and coping with failure for achievement motivation). All OMT responses were coded by one trained expert coder who had shown high coding reliability with OMT responses coded by coworkers of the authors of the OMT and in previous OMT studies. In addition, two trained student assistants coded parts of the sample to check the reliability of the coding procedures for the present sample. The first assistant coded OMT responses from 65 employees, and the second assistant coded OMT responses from another subsample of 81 employees. To determine the level of interrater reliability between the expert coder and the student-assistant coders, we calculated Gwet's $A C_{1}$ statistic (Gwet, 2008a, 2008b)—an improved version of Cohen's к (kappa)—using software provided by Gwet (2010). Interrater reliability between the expert coder and the OMT responses coded by the first assistant was .87 for affiliation, .76 for power, and .83 for achievement. For the second assistant, interrater reliability values with the expert coder were .89 for affiliation, .76 for power, and .90 for achievement.

In previous research, the OMT has been scored by summing up the answers for each motive. However, this approach does not fully capture the forced-choice nature of the scales. We therefore used a recently proposed item-response theory (IRT) method (Brown \& Maydeu-Olivares, 2011) for estimating the empirical IRT reliability and for scoring the OMT. This method suggests conceptualizing forced-choice situations as paired comparisons and applies Thurstone's (1927) theoretical framework for pairedcomparison data and accompanying methodology by adding the theoretical assumption that the utility of a paired comparison category is a linear function of a latent trait (Brown \& MaydeuOlivares, 2011). Effectively, the approach corrects for the fact that a higher score on one motive leads to a lower maximal possible score on another motive.

To apply paired-comparison methodology to forced-choice data, one must recode each forced-choice response (i.e., the answer to each of the pictures) into paired comparisons of the categories of interest. We therefore first grouped the OMT categories into four overarching categories that corresponded to the data categories that were of interest for the present study. The first three categories comprised the approach components of the motives of interest (power, achievement, and affiliation) and a fourth category included other responses (no motive-related response, avoidance responses, and in-between responses).

Most modern approaches for estimating individual differences in paired comparisons processes build on either structural equation methodology (Brown \& Maydeu-Olivares, 2011) or multilevel mixed-effects models (Böckenholt, 2001). We used the mixedeffects approach because the long format used by multilevel mixed-effects software can deal with the occurrence of missing or unbalanced numbers of paired comparisons for each picture (Bliese \& Ployhart, 2002) that was a natural consequence of the response format of the OMT (with four categories, participants provide information on three of the six possible paired comparisons in each response).

Applied to the OMT, the mixed-effects paired comparison model consists of a basic specification that is similar to applications of paired comparison models that do not differentiate between persons (e.g., Critchlow \& Fligner, 1991). Let $\mu_{i s}, \mu_{j s}, \mu_{k s}$, and $\mu_{l s}$ denote the mean evaluation of categories $\mathrm{i}, \mathrm{j}, \mathrm{k}$, and 1 by person $s$. The probit transformation of the probabilities to observe that each of these motive categories is preferred over the others by 
person $s-\pi_{i j s}, \pi_{i k s}, \pi_{i l s}, \pi_{j k s}, \pi_{j l s}$, and $\pi_{k l s}$-are then a function of the difference between the mean evaluations for these motive categories. This can be written as a probit model such that

$$
\left(\begin{array}{l}
\text { probit }\left(\pi_{\mathrm{ijs}}\right) \\
\operatorname{probit}\left(\pi_{\mathrm{iks}}\right) \\
\operatorname{probit}\left(\pi_{\mathrm{ils}}\right) \\
\operatorname{probit}\left(\pi_{\mathrm{jks}}\right) \\
\operatorname{probit}\left(\pi_{\mathrm{jls}}\right) \\
\operatorname{probit}\left(\pi_{k l s}\right)
\end{array}\right)=\left(\begin{array}{cccc}
1 & -1 & 0 & 0 \\
1 & 0 & -1 & 0 \\
1 & 0 & 0 & -1 \\
0 & 1 & -1 & 0 \\
0 & 1 & 0 & -1 \\
0 & 0 & 1 & -1
\end{array}\right)\left(\begin{array}{c}
\mu_{i s} \\
\mu_{j s} \\
\mu_{k s} \\
\mu_{l s}
\end{array}\right)=\mathbf{D}_{s} \mu_{s},
$$

where $\mathbf{D}_{s}$ is the design matrix and $\boldsymbol{\mu}_{s}$ is the corresponding vector of the mean evaluations. Note that the design matrix contains four dummy variables that each relate to one of the categories. One of these dummy variables (typically the last) can be omitted, and the corresponding row of $\boldsymbol{\mu}_{s}$ can be constrained to 0 without loss of generality (Böckenholt, 2001). Another feature of the model is that it has no intercept. Böckenholt (2001) provides a detailed description of this model. Note that Böckenholt uses a logit transformation (the Bradley-Terry model) in his 2001 paper instead of a probit transformation (the Thurstonian or Thurstone-Mosteller model; see Critchlow \& Fligner, 1991).

To account for individual differences in people's tendency to prefer motive categories over each other, one must add a random effect $v$ to three of the four mean evaluations. The fourth motive category must be constrained to identify the model and serves as a reference category (Böckenholt, 2001). The random effect $v$ captures the degree to which the preference of person $s$ for this category differs from the fixed effects for this motive category and makes the model an IRT model (De Boeck, 2008; Doran, Bates, Bliese, \& Dowling, 2007):

$$
\begin{aligned}
& \mu_{i s}=\mu_{i}+v_{i s} \\
& \mu_{j s}=\mu_{j}+v_{j s} \\
& \mu_{k s}=\mu_{k}+v_{k s} \\
& \mu_{l s}=0 .
\end{aligned}
$$

This basic model can be extended by adding a second random effect $w$ that captures the degree to which mean evaluations for picture $t$ differ from the fixed effects for the respective category. The resulting model predicts mean evaluations for person $s$ on picture $t$ :

$$
\begin{aligned}
& \mu_{i s t}=\mu_{i}+v_{i s}+w_{i t} \\
& \mu_{j s t}=\mu_{j}+v_{j s}+w_{j t} \\
& \mu_{k s t}=\mu_{k}+v_{k s}+w_{k t} \\
& \mu_{l s t}=0 .
\end{aligned}
$$

To score each of the motives, we fitted the described model using the glmer function in the lme4 package (Bates, Maechler, \& Bolker, 2011; De Boeck et al., 2011; Doran et al., 2007) in the R environment (R Development Core Team, 2011). In the glmer model specification syntax, the model is specified as response $\sim$ $0+\mathrm{d} 1+\mathrm{d} 2+\mathrm{d} 3+(0+\mathrm{d} 1+\mathrm{d} 2+\mathrm{d} 3$ I person $)+(0+\mathrm{d} 1+$ $\mathrm{d} 2+\mathrm{d} 3$ I picture). glmer estimates random effect scores (the latent motive scores) using the maximum a posteriori method (De Boeck et al., 2011).
To estimate the empirical IRT reliability for each of the motives, we first constrained the picture random effects for the respective other categories in the model in order to get standard errors that reflected the degree of uncertainty in picture content for the motive of interest (cf. De Boeck, 2008; Doran et al., 2007). In the second step, we estimated the variance and the quasi-standard errors of the person random effect for the respective motive $\left(v_{i s}, v_{j s}\right.$, or $\left.v_{k s}\right)$ using the qvealc package in the R environment (Firth, 2000, 2011). In the third step, we used the procedure described by DuToit (2003, also see Kim, 2012) and estimated the empirical IRT reliability by dividing the variance of the estimated latent trait scores by the sum of the variance of the estimated latent trait scores and the error variance (the error variance is equal to the mean of the squared standard errors). The resulting empirical IRT reliability coefficients indicate how closely the observed latent trait scores approximate the true latent trait scores (DuToit, 2003; Kim, 2012). The empirical IRT reliabilities were .71, .63, and .61 for the implicit power motive, affiliation motive, and achievement motive, respectively.

\section{Explicit (Self-Report) Measures}

Explicit self-report measures included not only the constructs we needed to test our hypotheses-extraversion and explicit achievement motivation- but also the other four constructs of the five-factor model as control variables. The four other dimensions of the five-factor model were included to ensure that the implicit motive measures and interactions between implicit motive measures and explicit constructs did not tap variance already explained by the five-factor model constructs.

We measured the five-factor model constructs with the German adaptation of the Big 5 Inventory (John et al., 2008; Rammstedt \& John, 2005). Participants rated the 45 items of this inventory on an answer scale ranging from 1 (strongly disagree) to 5 (strongly agree). Internal consistencies were $\alpha=.80, \alpha=.76, \alpha=.77, \alpha=$ .68 , and $\alpha=.85$, for neuroticism, openness, conscientiousness, agreeableness, and extraversion, respectively.

Explicit achievement was assessed with the hope for success scale of the revised Achievement Motives Scale (AMS-R-HS; Lang \& Fries, 2006). The items of this measure come from a scale originally developed by Gjesme (1974) that is based on McClelland et al.'s (1953) definition of achievement motivation as a recurrent concern with surpassing standards of excellence. The scale assesses to what degree persons associate positive affect with achievement situations, in which success and failure have approximately the same probability. Example items of the AMS-R-HS are "I enjoy situations, in which I can make use of my abilities" and "I am appealed by situations allowing me to test my abilities" (Lang \& Fries, 2006). The AMS-R-HS scale and adaptations of Gjesme's original version are regularly used in motivational research (e.g., Engeser \& Langens, 2010; Lang \& Fries, 2006; Sparfeldt \& Rost, 2011; Thrash, Elliot, \& Schultheiss, 2007; Ziegler, Schmukle, Egloff, \& Bühner, 2010), and there is evidence that the scale measures the same underlying construct as other measures of explicit achievement (Engeser \& Langens, 2010; Thrash et al., 2007). Research suggests that the scale is only weakly correlated to five-factor model constructs, and consequently is reasonably distinct from the five-factor model constructs (Engeser \& Langens, 2010; Ziegler et al., 2010). The items were 
rated on a scale ranging from 1 (strongly disagree) to 5 (strongly agree), and the internal consistency was $\alpha=.86$.

\section{Demographic Control Variables}

In addition to neuroticism, agreeableness, conscientiousness, and openness, we included age, gender, and educational attainment as control variables. Age and gender were included because explicit traits and implicit motives may change over the life course (McClelland et al., 1989; Roberts, Walton, \& Viechtbauer, 2006; Schultheiss, 2008) and because implicit motives may have a different developmental and hormonal basis in men and women (Hofer et al., 2010; McClelland et al., 1989; Schultheiss, 2008; Schultheiss et al., 2005).

Educational attainment served as a control variable because educational attainment is highly correlated with general mental ability (Neisser et al., 1996), which in turn is an important determinant of job performance (Schmidt \& Hunter, 1998). To assess educational attainment, we asked the employees to indicate their highest educational degree. For measurement purposes, we ordered these degrees into ordered categories ranging from low to high. This 13-point scale ranged from 0 (no degree) to 12 (doctoral degree). Similar measurement approaches have previously been used to measure educational attainment (Chapell et al., 2005; Snibbe \& Marcus, 2005).

\section{Supervisor Ratings of Task and Contextual Performance}

We measured task performance by asking supervisors to evaluate their employees with the German adaptation (Staufenbiel \& Hartz, 2000) of Williams and Anderson's (1991) in-role behavior scale $(\alpha=.83)$. Supervisors rated the five items on an answer scale ranging from 1 (strongly disagree) to 7 (strongly agree).

To measure contextual performance, we adopted an approach proposed by Judge, LePine, and Rich (2006), who suggested that con- textual and organizational citizenship behavior are overlapping to a degree that one could use an overall score from a heterogeneous set of organizational citizenship behavior items or scales as an indicator of contextual performance. Following this proposal, we used the overall score $(\alpha=.89)$ from Staufenbiel and Hartz's (2000) German adaptation of Podsakoff, MacKenzie, Moorman, and Fetter's (1990) Organizational Citizenship Behavior Inventory. The German adaptation of this inventory includes 20 items and includes the four subscales altruism, conscientiousness, sportsmanship, and civic virtue. Supervisors rated the items using response options ranging from 1 (strongly disagree) to 7 (strongly agree).

Staufenbiel and Hartz (2000) reported evidence from confirmatory factor analyses showing that their German adaptation of Williams and Anderson's (1991) Task Performance Scale and the four dimensions of their German adaptation of Podsakoff et al.'s (1990) Organizational Citizenship Behavior Scale capture distinct dimensions. To investigate the dimensionality of the measures in the present data, we conducted a confirmatory factor analysis using robust maximum likelihood estimation and the lavaan package (Rosseel, Oberski, \& Byrnes, 2011) for the R environment (R Development Core Team, 2011). We specified a model with a task performance factor and a second-order contextual performance factor (with the four organizational citizenship behavior constructs as first-order subdimensions). This model provided an acceptable fit to the data, $\chi^{2}(270, N=241)=423.03, p<.01$, comparative fit index $=.92$, root-mean-square error of approximation $=.05$, $90 \%$ CI $[.04, .06]$, standardized root-mean-square residual $=.07$.

\section{Results}

Table 2 provides descriptive information and intercorrelations for the study variables. For the implicit Big 3 motives, Table 2 contains the traditional (raw) motive scores (sum of the responses in each category) and the IRT-estimated motive scores from the Thurstonian IRT model. The scores calculated using the two

Table 2

Intercorrelations, Means, and Standard Deviations of the Study Variables

\begin{tabular}{|c|c|c|c|c|c|c|c|c|c|c|c|c|c|c|c|c|c|}
\hline Variable & 1 & 2 & 3 & 4 & 5 & 6 & 7 & 8 & 9 & 10 & 11 & 12 & 13 & 14 & 15 & 16 & 17 \\
\hline 1. Educational attainment & - & & & & & & & & & & & & & & & & \\
\hline 2. Age & -.09 & - & & & & & & & & & & & & & & & \\
\hline 3. Gender $($ male $=0$, female $=1)$ & -.16 & -.05 & - & & & & & & & & & & & & & & \\
\hline 4. Neuroticism & .02 & -.09 & .24 & - & & & & & & & & & & & & & \\
\hline 5. Openness & .03 & .08 & -.01 & -.14 & - & & & & & & & & & & & & \\
\hline 6. Conscientiousness & .09 & .13 & .17 & -.22 & .07 & - & & & & & & & & & & & \\
\hline 7. Agreeableness & -.01 & .12 & .03 & -.28 & .06 & .02 & - & & & & & & & & & & \\
\hline 8. Extraversion & .07 & -.05 & -.01 & -.12 & .39 & .19 & -.08 & - & & & & & & & & & \\
\hline 9. Explicit achievement & -.02 & -.01 & -.02 & -.22 & .26 & .16 & .15 & .18 & - & & & & & & & & \\
\hline 10. Implicit affiliation motive & -.10 & .09 & .07 & -.05 & -.07 & .07 & .10 & .00 & .00 & - & & & & & & & \\
\hline 11. Implicit power motive & .03 & .06 & -.06 & -.08 & -.04 & .07 & .05 & .02 & -.02 & .23 & - & & & & & & \\
\hline 12. Implicit achievement motive & .11 & .00 & .11 & -.12 & .13 & .08 & .03 & .08 & .09 & .24 & .46 & - & & & & & \\
\hline 13. Implicit affiliation motive (RS) & -.15 & .07 & .11 & -.04 & -.03 & .02 & .11 & .02 & .01 & .85 & -.21 & .02 & - & & & & \\
\hline 14. Implicit power motive (RS) & .04 & .03 & -.08 & -.03 & -.06 & .02 & .00 & .00 & -.04 & -.04 & .93 & .23 & -.46 & - & & & \\
\hline 15. Implicit achievement motive (RS) & .13 & -.06 & -.03 & -.12 & .17 & .09 & .01 & .08 & .09 & .11 & .03 & .85 & .06 & -.20 & - & & \\
\hline 16. Task performance & .20 & -.09 & .16 & -.01 & -.01 & .24 & -.05 & .05 & .02 & -.05 & .08 & .12 & -.09 & .06 & .10 & - & \\
\hline 17. Contextual performance & .16 & -.15 & .11 & -.14 & -.01 & .11 & .07 & .11 & .03 & -.10 & .03 & .08 & -.11 & .03 & .07 & .69 & - \\
\hline$M$ & 6.86 & 35.46 & 0.61 & 2.74 & 3.51 & 3.88 & 3.65 & 3.66 & 4.15 & 0.00 & 0.00 & 0.00 & 1.88 & 5.81 & 2.06 & 6.17 & 5.65 \\
\hline$S D$ & 2.70 & 10.91 & 0.49 & 0.63 & 0.53 & 0.56 & 0.48 & 0.66 & 0.66 & 1.00 & 1.00 & 1.00 & 1.16 & 2.12 & 1.07 & 0.77 & 0.71 \\
\hline
\end{tabular}

Note. $\quad N=241$. Correlations of $r \geq 1.13 \mid$ are significant at $p<.05$. RS $=$ raw score. 
methods were highly correlated for each motive. However, the pattern of intermotive correlations differed between the IRT scores and the raw scores. This finding is common because raw forcedchoice sum scores are biased by the fact that high scores on one scale limit the maximal possible values on other scales (Brown \& Maydeu-Olivares, 2011). We therefore used the IRT scores for all subsequent analyses. ${ }^{1}$

Table 3 and Table 4 show moderated multiple regression analyses that tested our hypotheses. In conducting these analyses, we followed recommendations by Aiken and West (1991) and centered $(M=0)$ all continuous independent variables to ease the interpretation of the interaction effects. All channeling effects were first tested separately and then jointly in overall models.

We began by examining Hypothesis 1, which suggested that extraversion channels the effect of the affiliation motive on task and contextual performance. As indicated by the regression analyses in Table 3 and Table 4, the affiliation motive interacted with extraversion in the prediction of both task and contextual performance. To examine whether the nature of this channeling effect was in line with our theoretical ideas, we graphed these interactions. Figure 1 shows that the relationship between the affiliation motive and the performance criteria was more positive when extraversion was high than when extraversion was low. These findings support Hypothesis 1 . Table 4 also shows that the affiliation motive tended to have a negative main effect on contextual performance at average levels of extraversion. This main effect was significant in the overall model (M7B) and suggests that the negative aspects of the affiliation motive for contextual performance are outweighed by the positive aspects of affiliation motivation only when people show high levels of extraversion.

We next turned to Hypothesis 2 and examined whether extraversion channeled the relationship of the power motive with task and contextual performance. Results revealed no significant channeling effects that supported this hypothesis (see Tables 3 and 4). Neither the predicted interaction of the implicit power motive with extraversion in the prediction of task performance nor the hypothesized channeling effect of extraversion on the relationship between the power motive and contextual performance emerged (Hypothesis 2 not supported).

We finally addressed Hypothesis 3. This hypothesis proposed that explicit achievement channels the implicit achievement motive in the prediction of task and contextual performance. In correspondence with this idea, the analyses provided in Table 3 and Table 4 found significant interaction effects between explicit achievement and the implicit achievement motive on task and contextual performance. The two interactions are graphed in Figure 2. As predicted by Hypothesis 3, the implicit achievement motive was more positively related to task and contextual when explicit achievement was high. Employees with corresponding implicit and explicit achievement dispositions (both high or both low) showed higher task and contextual performance.

In addition to examining each specific hypothesis, we were interested in the overall contribution of the implicit motive measures. Table 3 and Table 4 provide $R^{2}$ values for the full regression models and $\Delta R^{2}$ values indicating to what degree adding the implicit motive measures and channeling effects of explicit measures on implicit motives increased $R^{2}$. These values indicate that adding the channeling effects considerably increased the amount of explained criterion variance for both task performance $\left(\Delta R^{2}=\right.$
$.06)$ and contextual performance $\left(\Delta R^{2}=.08\right)$. In contrast, adding only the implicit measures led to considerably smaller changes in $\Delta R^{2}$ values, suggesting that the additionally explained variance largely originated from the hypothesized channeling effects.

\section{Discussion}

In this article, we developed theory and conducted empirical research showing that explicit traits (typical and stable behavioral tendencies of which people are aware) can function as behavioral channels for people's implicit motives (subconscious wishes and desires) such that explicit traits interact with implicit motives in the prediction of task and contextual performance at work. In our empirical study, the inclusion of theory-derived interactions between implicit motive measures and explicit trait measures considerably increased the explained criterion variance in task and contextual performance. This additionally explained variance resulted from a channeling effect of extraversion on the implicit wish for affiliation and a channeling effect of explicit achievement behavior on the implicit desire to achieve. We found no consistent support for a hypothesized channeling effect of extraversion on the implicit power motive's relationship with performance at work.

In addition to the hypothesized channeling effects, we found evidence for a negative main effect of the affiliation motive on contextual performance at average levels of extraversion in the overall model for contextual performance (with all hypothesized effects included). A possible explanation for the finding is that the drawbacks of affiliation motivation (e.g., being more rejecting toward unfamiliar people) are especially relevant for contextual performance. These drawbacks are outweighed by the advantages of affiliation motivation for contextual performance (e.g., being more friendly toward close persons) only when the affiliation motive is channeled by high levels of extraverted behavior (such that high-affiliation individuals easily establish close relationships to many people).

\footnotetext{
${ }^{1}$ For the sake of completeness, we examined to what degree the findings from our main analyses were similar when we used the traditional (raw) motive scores for the three motives instead of the motive scores from the Thurstonian IRT model in a series of supplementary analyses. In the separate regression analyses for each channeling effect, the pattern of findings was similar, but the $\Delta R^{2}$ values for the channeling effects tended to be smaller than in the analyses with the IRT scores $(.02, .00, .03, .02$, .00 , and .04 for M4A, M5A, M6A, M4B, M5B, and M6B, respectively). In the overall analyses with all hypothesized channeling effects (M7A and $\mathrm{M} 7 \mathrm{~B})$, the $\Delta R^{2}$ values were similar, but the variance in the overall analysis for contextual performance was distributed in a different manner such that the interaction between the power motive and extraversion was significan in this analysis, $t(225)=2.37$. Note that this interaction effect was a partial interaction effect in the sense that it explained no variance when the other hypothesized interaction effects were excluded (in M5A and M5B). It is consequently possible that this finding occurred because of variance that the raw score for power shared with the other two motives as a result of the forced-choice process (and that was corrected in the IRT model; cf. Brown \& Maydeu-Olivares, 2011; Böckenholt, 2001). We are consequently cautious in interpreting this finding also because the effect did not emerge when the other two significant channeling effects were excluded from the model.
} 
Table 3

Regression Analyses Testing Relationships Among Implicit Motives, Explicit Traits, and Task Performance

\begin{tabular}{|c|c|c|c|c|c|c|c|c|c|c|c|c|c|c|c|}
\hline \multirow[b]{2}{*}{ Parameter } & \multirow{2}{*}{$\begin{array}{l}\mathrm{M} 1 \mathrm{~A} \\
(b)\end{array}$} & \multirow{2}{*}{$\begin{array}{l}\mathrm{M} 2 \mathrm{~A} \\
(b)\end{array}$} & \multirow{2}{*}{$\begin{array}{c}\mathrm{M} 3 \mathrm{~A} \\
(b)\end{array}$} & \multicolumn{3}{|c|}{ M4A } & \multicolumn{3}{|c|}{ M5A } & \multicolumn{3}{|c|}{ M6A } & \multicolumn{3}{|c|}{ M7A } \\
\hline & & & & $b$ & $t(227)$ & $\beta$ & $b$ & $t(227)$ & $\beta$ & $b$ & $t(227)$ & $\beta$ & $b$ & $t(225)$ & $\beta$ \\
\hline Intercept & $5.99^{*}$ & $6.02^{*}$ & $6.01^{*}$ & 6.01 & $75.52 *$ & & 6.01 & $75.23^{*}$ & & 5.98 & $75.78^{*}$ & & 5.98 & $76.75^{*}$ & \\
\hline Educational attainment & $0.07^{*}$ & $0.06^{*}$ & $0.05^{*}$ & 0.05 & $2.78^{*}$ & .18 & 0.05 & $2.82^{*}$ & .18 & 0.05 & $2.84^{*}$ & .18 & 0.05 & $2.68^{*}$ & .17 \\
\hline $\begin{array}{l}\text { Gender }(\text { male }=0, \\
\quad \text { female }=1)\end{array}$ & $0.30^{*}$ & $0.25^{*}$ & $0.27^{*}$ & 0.27 & $2.58^{*}$ & .17 & 0.26 & $2.48^{*}$ & .17 & 0.30 & $2.84^{*}$ & .19 & 0.30 & $2.87^{*}$ & .19 \\
\hline Age & 0.00 & -0.01 & -0.01 & 0.00 & -1.02 & -.06 & 0.00 & -1.08 & -.07 & -0.01 & -1.14 & -.07 & -0.00 & -0.96 & -.06 \\
\hline Neuroticism & & -0.05 & -0.04 & -0.05 & -0.64 & -.04 & -0.04 & -0.52 & -.04 & -0.03 & -0.37 & -.03 & -0.05 & -0.57 & -.04 \\
\hline Openness & & -0.04 & -0.06 & -0.08 & -0.83 & -.06 & -0.07 & -0.70 & -.05 & -0.08 & -0.70 & -.05 & -0.09 & -0.90 & -.06 \\
\hline Conscientiousness & & $0.27^{*}$ & $0.27^{*}$ & 0.25 & $2.72^{*}$ & .18 & 0.28 & $2.93^{*}$ & .20 & 0.26 & $2.79^{*}$ & .19 & 0.24 & $2.64^{*}$ & .17 \\
\hline Agreeableness & & -0.09 & -0.08 & -0.09 & -0.84 & -.05 & -0.08 & -0.76 & -.05 & -0.08 & -0.74 & -.05 & -0.08 & -0.81 & -.05 \\
\hline Extraversion & & 0.00 & 0.01 & -0.01 & -0.26 & -.01 & 0.00 & 0.05 & .00 & 0.00 & 0.04 & .00 & -0.01 & 0.13 & -.01 \\
\hline Explicit achievement (EA) & & -0.01 & -0.01 & -0.03 & -0.36 & -.02 & -0.01 & -0.12 & -.01 & 0.00 & 0.02 & .00 & -0.02 & -0.26 & -.02 \\
\hline $\begin{array}{l}\text { Implicit affiliation motive } \\
\text { (nAff) }\end{array}$ & & & -0.06 & -0.05 & -1.06 & -.07 & -0.06 & -1.28 & -.08 & -0.09 & -1.61 & -.10 & -0.07 & -1.40 & -.09 \\
\hline $\begin{array}{l}\text { Implicit power motive } \\
\text { (nPower) }\end{array}$ & & & 0.03 & 0.04 & 0.75 & .05 & 0.04 & 0.80 & .06 & 0.04 & 0.74 & .05 & 0.05 & 0.87 & .06 \\
\hline $\begin{array}{l}\text { Implicit achievement } \\
\text { motive (nAch) }\end{array}$ & & & 0.08 & 0.07 & 1.2 & .09 & 0.07 & 1.24 & .09 & 0.08 & 1.40 & .10 & 0.07 & 1.23 & .09 \\
\hline Extraversion $\times$ nAff & & & & 0.20 & $2.98^{*}$ & .17 & & & & & & & 0.19 & $2.67^{*}$ & .16 \\
\hline Extraversion $\times$ nPower & & & & & & & 0.07 & 0.95 & .06 & & & & 0.01 & 0.11 & .01 \\
\hline $\mathrm{EA} \times \mathrm{nAch}$ & & & & & & & & & & 0.22 & $3.20^{*}$ & .19 & 0.20 & $3.03^{*}$ & .17 \\
\hline$R^{2}$ & .08 & .13 & .14 & .17 & & & .14 & & & .18 & & & .21 & & \\
\hline$F$ & $6.97^{*}$ & $3.67^{*}$ & $3.12^{*}$ & $3.66^{*}$ & & & $2.95^{*}$ & & & $3.78^{*}$ & & & $3.89^{*}$ & & \\
\hline$\Delta R^{2}$ vs. M3A & & & & .03 & & & .00 & & & .04 & & & .06 & & \\
\hline$\Delta F$ vs. M3A & & & & $8.88^{*}$ & & & 0.03 & & & $10.21^{*}$ & & & $6.11^{*}$ & & \\
\hline
\end{tabular}

Note. $\quad N=241$. To get standard errors for the $b$ and $\beta$ coefficients in M4A to M7A, divide the $b$ and $\beta$ coefficients by the $t$ values. Following recommendations by Aiken and West (1991, pp. 43-44), standardized coefficients ( $\beta$ ) were estimated by first standardizing all variables and then forming interaction terms such that the standardized interaction effects were products of standardized variables. $\mathrm{M}=$ model.

$* p<.05$

\section{Theoretical Contributions}

This paper makes a contribution to the literature by showing that channeling effects of explicit traits on implicit motives improve the prediction of task and contextual performance. These explanatory mechanisms have been considered in previous theoretical work on job performance (e.g., Bing, LeBreton, et al., 2007; Kanfer, 2009; Kehr, 2004), but we are not aware of any research that has empirically investigated the role of chan- neling effects in task and contextual performance. From a theoretical perspective, our findings suggest that conclusions regarding the role of personality in job performance may need to be revised and extended from a narrow perspective focusing on explicit traits to more comprehensive theoretical perspectives integrating explicit traits and implicit motives (e.g., Kanfer, 2009; Kehr, 2004). These revisions not only concern the magnitude of the role of personality characteristics but also
A

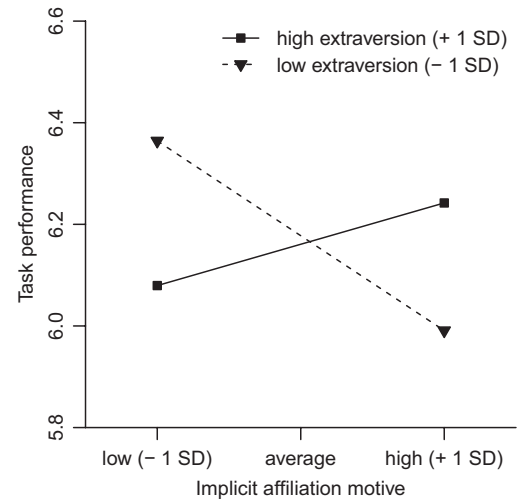

B

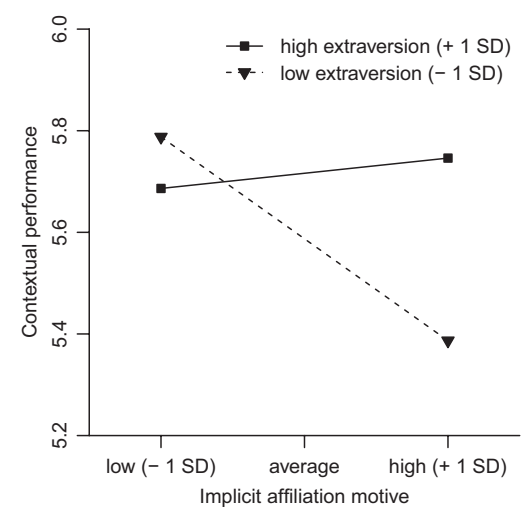

Figure 1. Interaction between the affiliation motive and extraversion in the prediction of (A) task performance and (B) contextual performance. Values are predicted values from M4A in Table 3 and M4B in Table 4. 


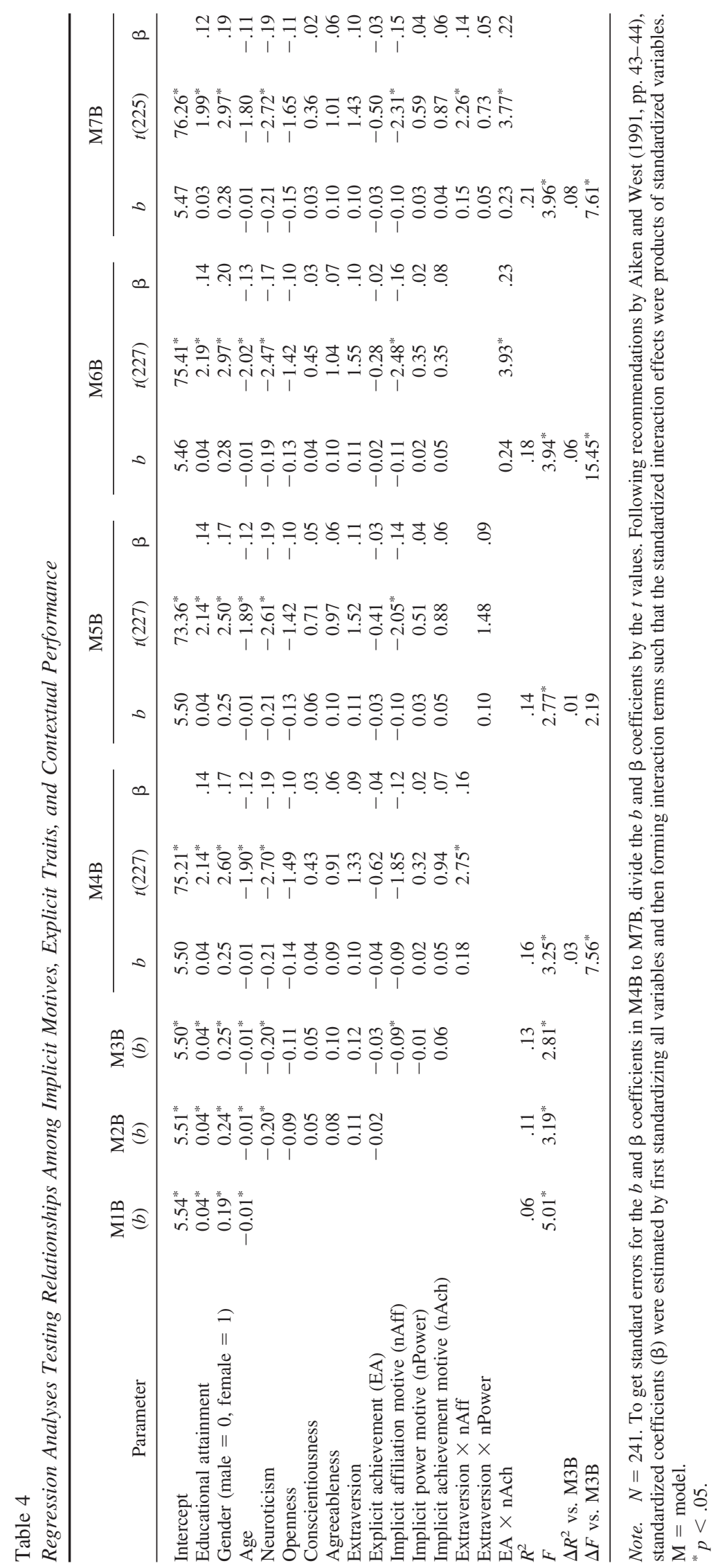


A

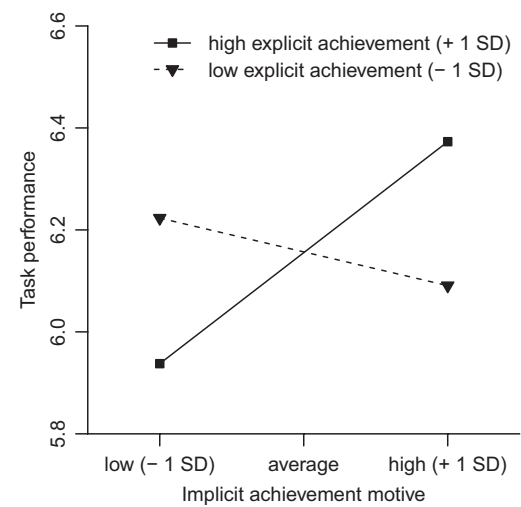

B

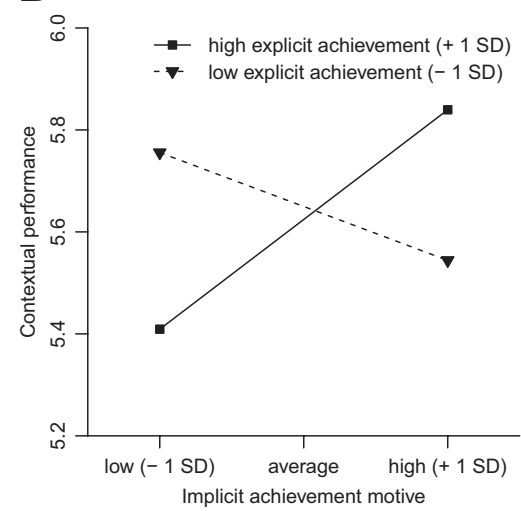

Figure 2. Interaction between the achievement motive and explicit achievement in the prediction of (A) task performance and (B) contextual performance. Values are predicted values from M6A in Table 3 and M6B in Table 4.

broaden the theoretical understanding of the mechanisms behind effects of personality traits on task and contextual performance. Our research supports the idea that a configurational approach focusing on discrepancies between implicit and explicit dispositions frequently provides meaningful additional insights. Our findings show that manifestations of extraverted and introverted behavior and high and low explicit achievement behavior in job performance can all lead to high performance when they correspond to implicit motivational needs of the person. These mechanisms provide an explanation for modest findings on the relationship between explicit traits and job performance (e.g., Morgeson et al., 2007) and especially for frequently disappointing findings on the relationship between extraversion and job performance criteria (e.g., Morgeson et al., 2007; Ones et al., 2007).

Our research represents another step toward integrating the trait and motive research traditions in the context of IO psychology. The two research traditions have long coexisted in IO research, and researchers have focused either on explicit traits (Barrick et al., 2001; Morgeson et al., 2007; Ones et al., 2007) or on implicit motives (e.g., House et al., 1991). Steps toward integrating the two traditions in the context of IO psychology have so far included overarching theoretical models (Bing, LeBreton et al., 2007; Kanfer, 2009; Kehr, 2004) and research on implicit and explicit aggression (Bing, Stewart, et al., 2007; Frost et al., 2007). This paper builds on this previous work and puts these research efforts further by extending the notion of explicit-implicit channeling effects to additional implicit and explicit constructs and to another measurement approach (research on implicit aggression has commonly used conditional reasoning tests instead of measures that rely on coding imaginative verbal behavior). Thereby, our research more generally establishes channeling effects as an important explanation for relationships between personality and job performance criteria.

This article also adds to the growing literature on the social meaning of work (Wrzesniewski et al., 2003). Our findings on the role of the affiliation motive and extraversion in job performance follow up on earlier theoretical ideas and qualitative findings (Wrzesniewski et al., 2003) suggesting that interpersonal interac- tions and social motives at work can have relevant positive and negative performance implications. Our study and the proposed theoretical model provide insights into how the social meaning of work influences employees' performance in positive and negative ways.

Finally, this article advances knowledge about the psychometric processes in measures of imaginative verbal behavior. This study is the first study of which we are aware that applied a Thurstonian IRT model to a measure of imaginative verbal behavior and that found internal consistency estimates higher than .60 in a full sample. Although desirable levels of internal consistency are commonly higher, these findings are encouraging because these values are considerably higher than previous findings on the internal consistency of measures of imaginative verbal behavior (typically below .40; e.g., Schultheiss et al., 2008). The values consequently represent a considerable improvement and suggest that conceptualizing measures of imaginative verbal behavior as forced-choice measures is a theoretically and psychometrically fruitful approach. The psychometric model we used is also useful because it extracts not only person random effects but also random motive (arousal) values for each picture (De Boeck, 2008). This feature of the model could be helpful for gaining insights into the degree to which pictures arouse specific motive categories and consequently for predicting reactions to pictures in future research and instrument development.

\section{Limitations}

One limitation is the correlational nature of this research. We have suggested that explicit traits and implicit motives influence job performance criteria. However, our research design is able to investigate only whether personality variables and job performance are associated. From a theoretical perspective, one could also think of a potential causal link between job performance and subsequent personality development over long periods of time.

A second limitation of our study relates to the survey nature of our research design. This design did not allow us to directly measure general mental ability. Although general mental ability is strongly correlated with educational attainment (Neisser et al., 
1996), a full general mental ability measure would likely be a better control variable.

A third limitation is the missing support for the predicted channeling effect of extraversion on the implicit power motive's relationship with performance at work. In our analyses using the IRT scores for the implicit motives, we found no evidence for a channeling effect of this type.

\section{Practical Implications and Future Directions}

Our research offers practical insights for employee development and personnel selection. For employee development, our findings are of interest because they provide an empirical basis for Kehr's (2004) claim that addressing discrepancies between implicit and explicit motives is a fruitful approach for developing employees. The psychological strategies that result from such an approach markedly differ from approaches that focus only on main effects of explicit personality traits on performance. Instead of focusing on altering or dealing with behavior affected by explicit traits, a developmental approach that builds on the notion of channeling can focus on reducing discrepancies between explicit traits and implicit motives. In so doing, leaders, IO psychologists, and coaches can build on previous research on the modification of implicit motives (see Rheinberg \& Engeser, 2010, for a review).

For personnel selection, practical implications are not direct in the sense that we outright recommend the use of measures that are based on coding imaginative verbal behavior in personnel selection at this point. We believe that there are two issues that may hinder their use in this context and that demand caution. First, measures that use imaginative verbal behavior require trained coders who spend very significant amounts of time in analyzing responses. In so doing, it is important that coders follow the established scoring manuals. In the context of clinical practice, maintaining the consistent quality of elaborated scoring procedures has proven to be difficult. Instead of following the established scoring manuals, clinical practitioners frequently use intuitive interpretations of responses that are not based on scientific research (Garb, Wood, Lilienfeld, \& Nezworski, 2002). The broad use of measures such as the OMT in personnel selection could lead to similar misuse of the procedure. Second, measures of imaginative verbal behavior are susceptible to situational arousal (Schultheiss \& Brunstein, 2010). Research would likely be needed to assess to what degree measures of imaginative verbal behavior work in high-stakes selection contexts and to determine what coding procedures could be useful in this specific context.

These issues notwithstanding, we believe that this research has two practical implications for personnel selection. First, we suggest that the current findings are informative for the development of new ways for measuring the Big 3 implicit motives that are easier to administer than measures of imaginative verbal behavior and that can be used in selection. Promising proposals include measures based on the implicit association test (IAT; Brunstein \& Schmitt, 2004) and conditional reasoning tests (Bing, LeBreton, et al., 2007). Research suggests that both types of measures can predict achievement-related behavior in the laboratory (Bing, LeBreton, et al., 2007; Brunstein \& Schmitt, 2004). Research that has investigated relations between measures of this type and measures that are based on coding imaginative verbal behavior is limited so far (for an initial small-scale study regarding the Brunstein-
Schmitt IAT, see Ziegler et al., 2010). We propose that the present research provides a basis for targeting measure such as the OMT as a reference point in future initial instrument development and validation.

Second, our research provides a basis for scoring narratives from applicants for motive content. Narratives from applicants are frequently available from published sources (e.g., yearbook) or are easy to derive (e.g., asking applicants to hand in autobiographies, vision statements, or motivation letters). Motivation researchers have long been aware that motive-scoring systems such as the OMT manual (Kuhl \& Scheffer, 2002) or scoring manuals developed for the Picture-Story Exercise (e.g., Winter, 1994) can be used to score imaginative content from running text and have used this approach for research (House et al., 1991; Winter, 1987). Recently, IO researchers have suggested using approaches of this type in organizations (Piccolo \& Latham, 2011; Rahael, Ragsdale, Christiansen, Hobart, \& Dutta, 2011). Selection tools based on narratives would still require significant amounts of coding but would be less or not affected by the high-stakes situation. In addition, narratives could be obtained without actually inviting applicants such that the information could be used at the initial stage of a multistage selection process. We believe that this is a fruitful avenue for future research.

\section{Conclusion}

Our goal in this paper was to broaden theoretical and empirical perspectives on the role of explicit traits and implicit motives in work performance. Our research suggests that considering not only explicit traits but also implicit motives provides important additional insights into the content and nature of motivational and personality processes that lead to high and also to reduced performance at work.

\section{References}

Aiken, L. S., \& West, S. G. (1991). Multiple regression: Testing and interpreting interactions. Newbury Park, CA: Sage.

Allport, G. W. (1937). Personality: A psychological interpretation. New York, NY: Holt, Rinehart, \& Winston.

Atkinson, J. W. (1982). Motivational determinants of thematic apperception. In A. J. Stewart (Ed.), Motivation and society (pp. 3-40). San Francisco, CA: Jossey-Bass.

Austin, J. T., \& Vancouver, J. B. (1996). Goal constructs in psychology: Structure, process, and content. Psychological Bulletin, 120, 338-375. doi:10.1037/0033-2909.120.3.338

Barrick, M. R., Mount, M. K., \& Judge, T. A. (2001). Personality and performance at the beginning of the new millennium: What do we know and where do we go next? International Journal of Selection and Assessment, 9, 9-30. doi:10.1111/1468-2389.00160

Bates, D., Maechler, M., \& Bolker, B. (2011). lme4: Linear mixed-effects models using S4 classes (Version 0.999375-41) [Computer software]. Vienna, Austria: R Foundation for Statistical Computing. Retrieved from http://cran.r-project.org

Baumann, N., Kaschel, R., \& Kuhl, J. (2005). Striving for unwanted goals: Stress-dependent discrepancies between explicit and implicit achievement motives reduce subjective well-being and increase psychosomatic symptoms. Journal of Personality and Social Psychology, 89, 781-799. doi:10.1037/0022-3514.89.5.781

Bing, M. N., LeBreton, J. M., Davison, H. K., Migetz, D. Z., \& James, L. R. (2007). Integrating implicit and explicit social cognitions for 
enhanced personality assessment: A general framework for choosing measurement and statistical methods. Organizational Research Methods, 10, 346-389. doi:10.1177/1094428107301148

Bing, M. N., Stewart, S. M., Davison, H. K., Green, P. D., McIntyre, M. D., \& James, L. R. (2007). An integrative typology of personality assessment for aggression: Implications for predicting counterproductive workplace behavior. Journal of Applied Psychology, 92, 722-744. doi: 10.1037/0021-9010.92.3.722

Bliese, P. D., \& Ployhart, R. E. (2002). Growth modeling using random coefficient models: Model building, testing and illustrations. Organizational Research Methods, 5, 362-387. doi:10.1177/109442802237116

Böckenholt, U. (2001). Hierarchical models of paired comparison data. Psychological Methods, 6, 49-66. doi:10.1037/1082-989X.6.1.49

Borman, W. C., \& Motowidlo, S. J. (1997). Task performance and contextual performance: The meaning for personnel selection research. Human Performance, 10, 99-109. doi:10.1207/s15327043hup1002_3

Brown, A., \& Maydeu-Olivares, A. (2011). Item response modeling of forced-choice questionnaires. Educational and Psychological Measurement, 71, 460-502. doi:10.1177/0013164410375112

Brunstein, J. C., \& Maier, G. W. (2005). Implicit and self-attributed motives to achieve: Two separate but interacting needs. Journal of Personality and Social Psychology, 89, 205-222. doi:10.1037/00223514.89.2.205

Brunstein, J. C., \& Schmitt, C. H. (2004). Assessing individual differences in achievement motivation with the implicit association test. Journal of Research in Personality, 38, 536-555. doi:10.1016/j.jrp.2004.01.003

Burdick, H. A., \& Burnes, A. J. (1958). A test of "strain toward symmetry" theories. Journal of Abnormal and Social Psychology, 57, 367-370. doi: $10.1037 / \mathrm{h} 0041999$

Byrne, D. (1961). Interpersonal attraction as a function of affiliation need and attitude similarity. Human Relations, 14, 283-289. doi:10.1177/ 001872676101400305

Byrne, D. (1962). Response to attitude similarity-dissimilarity as a function of affiliation need. Journal of Personality, 30, 164-177. doi: 10.1111/j.1467-6494.1962.tb01683.x

Chapell, M. S., Blanding, Z. B., Silverstein, M. E., Takahashi, M., Newman, B., Gubi, A., \& McCann, N. (2005). Test anxiety and academic performance in undergraduate and graduate students. Journal of Educational Psychology, 97, 268-274. doi:10.1037/0022-0663.97.2.268

Critchlow, D. E., \& Fligner, M. A. (1991). Paired comparisons, triple comparison, and ranking experiments as generalized linear models, and their implementation on GLIM. Psychometrika, 56, 517-533. doi: 10.1007/BF02294488

De Boeck, P. (2008). Random item IRT models. Psychometrika, 73, 533-559. doi:10.1007/s11336-008-9092-x

De Boeck, P., Bakker, M., Zwitser, R., Nivard, M., Hofman, A., Tuerlinckx, F., \& Partchev, I. (2011). The estimation of item response models with the lmer function from the lme4 package in R. Journal of Statistical Software, 39, 1-28. Retrieved from http://www.jstatsoft.org/v39/i12

Donnellan, M. B., Lucas, R. E., \& Fleeson, W. (Eds.). (2009). Personality and assessment at age 40: Reflections on the past person-situation debate and emerging directions of future person-situation integration [Special issue]. Journal of Research in Personality, 43(2). doi:10.1016/ j.jrp.2009.02.010

Doran, H., Bates, D., Bliese, P. D., \& Dowling, M. (2007). Estimating the multilevel Rasch model: With the lme4 package. Journal of Statistical Software, 20, 1-18. Retrieved from http://www.jstatsoft.org/v20/i02

DuToit, M. (2003). IRT from SSI: BILOG-MG, MULTILOG, PARSCALE, TESTFACT. Lincolnwood, IL: Scientific Software International.

Emmons, R. A. (1989). Exploring the relations between motives and traits: The case of narcissism. In D. Buss \& N. Cantor (Eds.), Personality psychology: Recent trends and emerging directions (pp. 32-44). New York, NY: Springer.

Engeser, S., \& Langens, T. (2010). Mapping explicit social motives of achievement, power, and affiliation onto the five-factor model of personality. Scandinavian Journal of Psychology, 51, 309-318. doi: 10.1111/j.1467-9450.2009.00773.x

Entwisle, D. R. (1972). To dispel fantasies about fantasy-based measures of achievement motivation. Psychological Bulletin, 77, 377-391. doi: $10.1037 / \mathrm{h} 0020021$

Exline, R. V. (1963). Explorations in the process of person perception: Visual interaction in relation to competition, sex, and need for affiliation Journal of Personality, 31, 1-20. doi:10.1111/j.1467-6494.1963 tb01836.x

Firth, D. (2000). Quasi-variances in Xlisp-Stat and on the web. Journal of Statistical Software, 5(4), 1-13. Retrieved from http://www.jstatsoft.org/ v05/i04

Firth, D. (2011). qvealc: Quasi variances for factor effects in statistical models (version 0.8-7). [Computer software]. Vienna, Austria: The R Foundation for Statistical Computing. Retrieved from http://cran.rproject.org

Frost, B. C., Ko, C.-H. E., \& James, L. R. (2007). Implicit and explicit personality: A test of the channeling hypothesis for aggressive behavior. Journal of Applied Psychology, 92, 1299-1319. doi:10.1037/00219010.92.5.1299

Garb, H. N., Wood, J. M., Lilienfeld, S. O., \& Nezworski, M. T. (2002). Effective use of projective techniques in clinical practice: Let the data help with selection and interpretation. Professional Psychology: Research and Practice, 33, 454-463. doi:10.1037/0735-7028.33.5.454

Gjesme, T. (1974). Goal distance in time and its effects on the relations between achievement motives and performance. Journal of Research in Personality, 8, 161-171. doi:10.1016/0092-6566(74)90017-8

Guion, R. M., \& Gottier, R. F. (1965). Validity of personality measures in personnel selection. Personnel Psychology, 18, 135-164. doi:10.1111/ j.1744-6570.1965.tb00273.x

Gwet, K. L. (2008a). Computing inter-rater reliability and its variance in the presence of high agreement. British Journal of Mathematical and Statistical Psychology, 61, 29-48. doi:10.1348/000711006X126600

Gwet, K. L. (2008b). Variance estimation of nominal-scale inter-rater reliability with random selection of raters. Psychometrika, 73, 407-430. doi:10.1007/s11336-007-9054-8

Gwet, K. L. (2010). AgreeStat: Statistical analysis of the extent of agreement among multiple raters [Computer software]. Gaithersburg, MD Advanced Analytics Press. Retrieved from http://www.agreestat.com/ agreestat_excel.html

Hagemeyer, B., \& Neyer, F. J. (2012). Assessing implicit motivational orientations in couple relationships: The Partner-related Agency and Communion Test (PACT). Psychological Assessment, 24, 114-128. doi: $10.1037 / \mathrm{a} 0024822$

Hardy, K. R. (1957). Determinants of conformity and attitude change. Journal of Abnormal and Social Psychology, 54, 289-294. doi:10.1037/ h0048374

Heckhausen, H. (1963). Hoffnung und Furcht in der Leistungsmotivation [Hope for success in achievement motivation]. Meisenheim am Glan, Germany: Anton Hain.

Hofer, J., Busch, H., Bond, M. H., Campos, D., Li, M., \& Law, R. (2010). The implicit power motive and sociosexuality in men and women Pancultural effects of responsibility. Journal of Personality and Social Psychology, 99, 380-394. doi:10.1037/a0020053

House, R. J., Spangler, W. D., \& Woycke, J. (1991). Personality and charisma in the U.S. presidency: A psychological theory of leader effectiveness. Administrative Science Quarterly, 36, 364-396. doi: $10.2307 / 2393201$

John, O. P., Naumann, L. P., \& Soto, C. J. (2008). Paradigm shift to the integrative Big Five trait taxonomy. In O. P. John, R. W. Robins, \& L. A Pervin (Eds.), Handbook of personality (3rd ed., pp. 114-158). New York, NY: Guilford Press.

Johnson, R. E., \& Tan, J. A. (2009). Explicit reasons for examining the 
implicit motive system. Industrial and Organizational Psychology, 2, 103-105. doi:10.1111/j.1754-9434.2008.01115.x

Judge, T. A., LePine, J. A., \& Rich, B. L. (2006). Loving yourself abundantly: Relationship of the narcissistic personality to self- and other perceptions of workplace deviance, leadership, and task and contextual performance. Journal of Applied Psychology, 91, 762-776. doi:10.1037/ 0021-9010.91.4.762

Kanfer, R. (2009). Work motivation: Identifying use-inspired research directions. Industrial and Organizational Psychology, 2, 77-93. doi: 10.1111/j.1754-9434.2008.01112.x

Kehr, H. M. (2004). Integrating implicit motives, explicit motives, and perceived abilities: The compensatory model of work motivation and volition. Academy of Management Review, 29, 479-499. doi:10.2307/ 20159055

Kim, S. (2012). A note on the reliability coefficients for item response model-based ability estimates. Psychometrika, 77, 153-162. doi: 10.1007/s11336-011-9238-0

Kuhl, J., \& Kazén, M. (2008). Motivation, affect, and hemispheric asymmetry: Power versus affiliation. Journal of Personality and Social Psychology, 95, 456-469. doi:10.1037/0022-3514.95.2.456

Kuhl, J., \& Scheffer, D. (2002). Der operante Multi-Motiv-Test (OMT): Manual [The operant multi-motive-test (OMT): Manual]. Osnabrück, Germany: University of Osnabrück.

Kukla, A. (1978). An attributional theory of choice. Advances in Experimental Social Psychology, 11, 113-144. doi:10.1016/S00652601(08)60006-4

Lang, J., Bliese, P. D., Lang, J. W. B., \& Adler, A. B. (2011). Work gets unfair for the depressed: Cross-lagged relations between organizational justice perceptions and depressive symptoms. Journal of Applied Psychology, 96, 602-618. doi:10.1037/a0022463

Lang, J. W. B., \& Fries, S. (2006). A revised 10-item version of the Achievement Motives Scale: Psychometric properties in Germanspeaking samples. European Journal of Psychological Assessment, 22, 216-224. doi:10.1027/1015-5759.22.3.216

Langner, C. A., \& Winter, D. G. (2001). The motivational basis of concessions and compromise: Archival and laboratory studies. Journal of Personality and Social Psychology, 81, 711-727. doi:10.1037/00223514.81.4.711

McClelland, D. C. (1951). Personality. New York, NY: Sloane.

McClelland, D. C. (1993). Intelligence is not the best predictor of job performance. Current Directions in Psychological Science, 2, 5-6. doi:10.1111/1467-8721.ep10770447

McClelland, D. C., Atkinson, J. W., Clark, R. A., \& Lowell, E. L. (1953). The achievement motive. East Norwalk, CT: Appleton-Century-Crofts.

McClelland, D. C., Koestner, R., \& Weinberger, J. (1989). How do self-attributed and implicit motives differ? Psychological Review, 96, 690-702. doi:10.1037/0033-295X.96.4.690

Morgeson, F. P., Campion, M. A., Dipboye, R. L., Hollenbeck, J. R., Murphy, K., \& Schmitt, N. (2007). Are we getting fooled again? Coming to terms with limitations in the use of personality tests for personnel selection. Personnel Psychology, 60, 1029-1049. doi:10.1111/j.17446570.2007.00100.x

Morgeson, F. P., \& Humphrey, S. E. (2006). The Work Design Questionnaire (WDQ): Developing and validating a comprehensive measure for assessing job design and the nature of work. Journal of Applied Psychology, 91, 1321-1339. doi:10.1037/0021-9010.91.6.1321

Murray, H. A. (1938). Explorations in personality. New York, NY: Oxford University Press

Neisser, U., Boodoo, G., Bouchard, T. J., Boykin, A. W., Brody, N., Ceci, S. J., . . Urbina, S. (1996). Intelligence: Knowns and unknowns. American Psychologist, 51, 77-101. doi:10.1037/0003-066X.51.2.77

Nicholls, J. G. (1984). Achievement motivation: Conceptions of ability, subjective experience, task choice, and performance. Psychological Review, 91, 328-346. doi:10.1037/0033-295X.91.3.328
Ones, D. S., Dilchert, S., Viswesvaran, C., \& Judge, T. A. (2007). In support of personality assessment in organizational settings. Personnel Psychology, 60, 995-1027. doi:10.1111/j.1744-6570.2007 .00099.x

Pang, J. S. (2006). A revised content-coding measure for hope of success $(H S)$ and fear of failure ( $F F)$ (Unpublished doctoral dissertation). University of Michigan, Ann Arbor.

Pervin, L. A. (1994a). A critical analysis of current trait theory. Psychological Inquiry, 5, 103-113. doi:10.1207/s15327965pli0502_1

Pervin, L. A. (1994b). Further reflections on current trait theory. Psychological Inquiry, 5, 169-178. doi:10.1207/s15327965pli0502_19

Piccolo, R. F., \& Latham, G. P. (2011, April). A content analysis approach to measuring subconscious motives. In N. A. Bowling \& R. E. Johnson (Chairpersons), Measuring implicit processes in organizational research. Symposium conducted at the conference of the Society of Industrial and Organizational Psychology, Chicago, IL.

Podsakoff, P. M., MacKenzie, S. B., Moorman, R. H., \& Fetter, R. (1990). Transformational leader behaviors and their effects on followers' trust in leader, satisfaction, and organizational citizenship behavior. Leadership Quarterly, 1, 107-142. doi:10.1016/1048-9843(90)90009-7

Rahael, J., Ragsdale, J. M., Christiansen, N. D., Hobart, K. P., \& Dutta, S. (2011, April). Using work narratives to assess motives dispositions in the workplace. In N. A. Bowling \& R. E. Johnson (Chairpersons), Measuring implicit processes in organizational research. Symposium conducted at the conference of the Society of Industrial and Organizational Psychology, Chicago, IL.

Rammstedt, B., \& John, O. P. (2005). Kurzversion des Big Five Inventory (BFI-K): Entwicklung und Validierung eines ökonomischen Inventars zur Erfassung der fünf Faktoren der Persönlichkeit [Short version of the Big Five Inventory (BFI-K): Development and validation of an economic inventory for assessment of the five factors of personality]. Diagnostica, 51, 195-206. doi:10.1026/0012-1924.51.4.195

R Development Core Team. (2011). R: A language and environment for statistical computing (version 2.13.0) [Computer software]. Vienna, Austria: R Foundation for Statistical Computing. Retrieved from http:// www.r-project.org

Rheinberg, F., \& Engeser, S. (2010). Motive training and motivational competence. In O. C. Schultheiss \& J. C. Brunstein (Eds.), Implicit motives (pp. 510-548). Oxford, England: University Press.

Roberts, B. W., \& DelVecchio, W. F. (2000). The rank-order consistency of personality traits from childhood to old age: A quantitative review of longitudinal studies. Psychological Bulletin, 126, 3-25. doi:10.1037/ 0033-2909.126.1.3

Roberts, B. W., Walton, K. E., \& Viechtbauer, W. (2006). Patterns of mean-level change in personality traits across the life course: A metaanalysis of longitudinal studies. Psychological Bulletin, 132, 1-25. doi: 10.1037/0033-2909.132.1.1

Rosseel, Y., Oberski, D., \& Byrnes, J. (2011). lavaan: Latent variable analysis (version 0.4-10) [Computer software]. Vienna, Austria: R Foundation for Statistical Computing. Retrieved from http://www.r-project.org

Sackett, P. R., \& Lievens, F. (2008). Personnel selection. Annual Review of Psychology, 59, 419-450. doi:10.1146/annurev.psych.59.103006.093716

Scheffer, D., Kuhl, J., \& Eichstaedt, J. (2003). Der Operante Motiv-Test (OMT): Inhaltsklassen, Auswertung, psychometrische Kennwerte und Validierung [The operant motive test (OMT): Contents, scoring, psychometric values, and validation]. In J. Stiensmeier-Pelster \& F. Rheinberg (Eds.), Diagnostik von Motivation und Selbstkonzept [Diagnostic of motivation and self-concept] (pp. 151-167). Göttingen, Germany: Hogrefe.

Schmidt, F. L., \& Hunter, J. E. (1998). The validity and utility of selection methods in personnel psychology: Practical implications of 85 years of research findings. Psychological Bulletin, 124, 262-274. doi:10.1037/ 0033-2909.124.2.262

Schultheiss, O. C. (2008). Implicit motives. In O. P. John, R. W. Robins, 
\& L. A. Pervin (Eds.), Handbook of personality: Theory and research (3rd ed., pp. 603-633). New York, NY: Guilford Press.

Schultheiss, O. C., \& Brunstein, J. C. (2002). Inhibited power motivation and persuasive communication: A lens model analysis. Journal of Personality, 70, 553-582. doi:10.1111/1467-6494.05014

Schultheiss, O. C., \& Brunstein, J. C. (2010). Introduction. In O. C. Schultheiss \& J. C. Brunstein (Eds.), Implicit motives (pp. ix-Xxvii). New York, NY: Oxford University Press.

Schultheiss, O. C., Liening, S. H., \& Schad, D. (2008). The reliability of a Picture Story Exercise measure of implicit motives: Estimates of internal consistency, retest reliability, and ipsative stability. Journal of Research in Personality, 42, 1560-1571. doi:10.1016/j.jrp.2008.07.008

Schultheiss, O. C., \& Pang, J. S. (2007). Measuring implicit motives. In R. W. Robins, R. C. Fraley, \& R. Krueger (Eds.), Handbook of research methods in personality psychology (pp. 322-344). New York, NY: Guilford Press.

Schultheiss, O. C., Wirth, M. M., Torges, C. M., Pang, J. S., Villacorta, M. A., \& Welsh, K. M. (2005). Effects of implicit power motivation on men's and women's implicit learning and testosterone changes after social victory or defeat. Journal of Personality and Social Psychology, 88, 174-188. doi:10.1037/0022-3514.88.1.174

Sheldon, K. M., Ryan, R. M., Deci, E. L., \& Kasser, T. (2004). The independent effects of goal contents and motives on well-being: It's both what you pursue and why you pursue it. Personality and Social Psychology Bulletin, 30, 475-486. doi:10.1177/0146167203261883

Snibbe, A. C., \& Marcus, H. R. (2005). You can't always get what you want: Educational attainment, agency, and choice. Journal of Personality and Social Psychology, 88, 703-720. doi:10.1037/00223514.88.4.703

Spangler, W. D. (1992). Validity of questionnaire and TAT measures of need for achievement: Two meta-analyses. Psychological Bulletin, 112, 140-154. doi:10.1037/0033-2909.112.1.140

Sparfeldt, J. R., \& Rost, D. H. (2011). Content-specific achievement motives. Personality and Individual Differences, 50, 496-501. doi: 10.1016/j.paid.2010.11.016

Staufenbiel, T., \& Hartz, C. (2000). Organizational Citizenship Behavior: Entwicklung und Validierung eines ersten Messinstruments [Organizational citizenship behavior: Development and validation of a measurement instrument]. Diagnostica, 46, 73-83. doi:10.1026//0012-1924.46.2.73

Tett, R. P., \& Christiansen, N. D. (2007). Personality tests at the crossroads: A response to Morgeson, Campion, Dipboye, Hollenbeck, Murphy, and Schmitt (2007). Personnel Psychology, 60, 967-993. doi: 10.1111/j.1744-6570.2007.00098.x
Thrash, T. M., Elliot, A. J., \& Schultheiss, O. C. (2007). Methodological and dispositional predictors of congruence between implicit and explicit need for achievement. Personality and Social Psychology Bulletin, 33, 961-974. doi:10.1177/0146167207301018

Thurstone, L. L. (1927). A law of comparative judgment. Psychological Review, 34, 273-286. doi:10.1037/h0070288

Trope, Y. (1986). Self-enhancement and self-assessment in achievement behavior. In R. M. Sorrentino \& E. T. Higgins (Eds.), Handbook of motivation and cognition: Foundations of social behavior (pp. 350378). New York, NY: Guilford Press.

Tuerlinckx, F., De Boeck, P., \& Lens, W. (2002). Measuring needs with the Thematic Apperception Test: A psychometric study. Journal of Personality and Social Psychology, 82, 448-461. doi:10.1037/00223514.82.3.448

Williams, L. J., \& Anderson, S. E. (1991). Job satisfaction and organizational commitment as predictors of organizational citizenship and in-role behavior. Journal of Management, 17, 601-617. doi:10.1177/ 014920639101700305

Winter, D. G. (1987). Leader appeal, leader performance, and the motive profiles of leaders and followers: A study of American presidents and elections. Journal of Personality and Social Psychology, 52, 196-202. doi:10.1037/0022-3514.52.1.196

Winter, D. G. (1994). Manual for scoring motive imagery in running text. Unpublished manuscript, Department of Psychology, University of Michigan, Ann Arbor.

Winter, D. G., John, O. P., Stewart, A. J., Klohnen, E. C., \& Duncan, L. E. (1998). Traits and motives: Toward an integration of two traditions in personality research. Psychological Review, 105, 230-250. doi:10.1037/ 0033-295X.105.2.230

Wrzesniewski, A., Dutton, J. E., \& Debebe, G. (2003). Interpersonal sensemaking and the meaning of work. Research in Organizational Behavior, 25, 93-135. doi:10.1016/S0191-3085(03)25003-6

Yukl, G., \& Falbe, C. M. (1990). Influence tactics and objectives in upward, downward, and lateral influence attempts. Journal of Applied Psychology, 75, 132-140. doi:10.1037/0021-9010.75.2.132

Ziegler, M., Schmukle, S., Egloff, B., \& Bühner, M. (2010). Investigating measures of achievement motivation(s). Journal of Individual Differences, 31, 15-21. doi:10.1027/1614-0001/a000002

Received June 2, 2011

Revision received June 13, 2012

Accepted June 26, 2012 